\title{
REVIEW ARTICLE; ANTICANCER ACTIVITIES OF SOME FUSED HETEROCYCLIC MOIETIES CONTAINING NITROGEN AND/OR SULFUR HETEROATOMS \\ Asmaa M. Omar ${ }^{\mathrm{b}}$, Nashwa M. Saleh ${ }^{\mathrm{a}}$, Adel A-H.Abdel-Rahman ${ }^{\mathrm{b}}$, Khaled El-Adl ${ }^{\mathrm{c}, \mathrm{d}, *}$ \\ ${ }^{a}$ Department of Chemistry, Faculty of Science, Al-Azhar University (Girls Branch), Youssef Abbas Str., Cairo, Egypt \\ b Department of Chemistry, Faculty of Science, Menoufia University, Shebin El-Koam, Egypt \\ ${ }^{\mathbf{c}}$ Department of Pharmaceutical Chemistry, Faculty of Pharmacy, Al-Azhar University, Cairo, Egypt \\ ${ }^{\mathbf{d}}$ Department of Pharmaceutical Chemistry, Faculty of Pharmacy, Heliopolis University for Sustainable Development, Cairo, Egypt
}

\section{Corresponding Author: eladlkhaled74@azhar.edu.eg; khaled.eladl@hu.edu.eg ABSTRACT}

Cancer cells often have a high demand for antiapoptotic proteins in order to resist programmed cell death. Heterocyclic compounds present themselves as a fundamental division of organic chemistry. Most clinically effective antitumor agents are inhibitors of DNA, RNA or protein synthesis, enzyme inhibition and/or interfere with the metabolism of other cell components, frequently lacking or displaying poor selective antitumor activity. The majority of heterocycle compounds and typically common heterocycle fragments present in most pharmaceuticals currently marketed, alongside with their intrinsic versatility and unique physicochemical properties have poised them as true cornerstones of medicinal chemistry. The $S$-heterocyclic core (Thiophene) has been reported to possess significant importance in various fields from medicinal chemistry. Many diverse biologically active products were prepared, several of which exhibited antimicrobial, analgesic, anti-inflammatory, antioxidant, antitumor, local anesthetic, anticoagulant and antithrombotic activities. Many $N$-heterocyclic compounds that are broadly distributed in Nature, possess physiological and pharmacological properties and are constituents of many biologically important molecules, including many vitamins, nucleic acids, pharmaceuticals, antibiotics, dyes and agrochemicals, amongst many others. The base pairs of DNA and RNA (Guanine, cytosine, adenine, and thymine) are also made up of $N$-heterocyclic compounds, namely purines, pyrimidines, etc. These nitrogen-containing heterocyclic molecules with distinct characteristics and applications have gained prominence in the rapidly expanding fields of organic and medicinal chemistry and the pharmaceutical industry. Finally, many of these compounds have higher activity against cancer cells using the standard MTT (3-(4,5-dimethylthiazol-2-yl)-2,5-diphenyltetrazolium bromide)assay.

KEYWORDS: Heterocyclic compounds; Breast cancer; Hepatocellular carcinoma; Nitrogen and/or Sulfur-based heterocycles. 


\section{INTRODUCTION}

Heterocycle-containing molecules are extensively studied for their synthesis and their applications not only in medicinal chemistry, but also in optics, electronics and material sciences. Therefore, in the last decade, considerable efforts have been performed in designing and carrying out innovative synthetic protocols in heterocyclic chemistry to optimize more eco-sustainable approaches. These processes, also called green chemistry, have been applied not only in the field of medicinal chemistry, but also to natural products, polymer syntheses, material sciences, nanotechnology, essential oil extraction and biochemical processes (Driowya et al., 2016).

A vast number of heterocyclic derivatives observed in natural products have been reported. On the other side, they find increasing applications such as superconductors, optoelectronics, light emission diodes LEDs, and non-linear optical (NLO) chromophores. Besides, their pharmacological profiles as antimicrobial, antifungal, anti-inflammatory, anti-proliferative and antioxidant agents have led to an enduring interest in the development of various methods for their synthesis (Shams, et al., 2011).

Heterocyclic compounds present themselves as a fundamental division of organic chemistry. Defined by IUPAC as "cyclic compounds having as ring atoms of at least two different elements", heterocycles' ring structures are in essence composed by elements other than carbon, where the most frequent substituents are oxygen, nitrogen and sulfur. According to the heteroatom(s) present in the ring structures, heterocycles can be classified as oxygen, nitrogen or sulfur based and, within each class, compounds are organized based on the size of the ring structure size determined by the total number of atoms. The type and size of ring structures, together with the substituent groups of the core scaffold, impact strongly on the physicochemical properties. Among the various clinical applications, heterocyclic compounds have a considerable active role as anti-bacterial, anti-viral, antifungal, anti-inflammatory, and anti-tumor drugs (Martins et al., 2015).

Most clinically effective antitumor agents are inhibitors of DNA, RNA or protein synthesis, enzyme inhibition and/or interfere with the metabolism of other cell components, frequently lacking or displaying poor selective antitumor activity. These traditional antitumor agents often poorly discriminate between tumor and normal non-tumor cells, especially those with high proliferative potential. A number of novel technologies, including antibody-drug conjugates, transporter-related tumor targeting of small anticancer drugs, prodrugs of anticancer agents, targeting of agents to defined (Cancer) tissues, or specific delivery systems for anticancer drugs, have recently become subject of extensive investigations to improve anticancer selectivity (Thomas et al., 2017).

Functional groups containing heteroatom-heteroatom bonds $(X-X$, where $X=N, O$, $\mathrm{S}$, and $\mathrm{P}$ ) have been identified in natural products isolated from a variety of sources (Fig. 1). The diverse structures and reactivities of these motifs have captured the attention of chemists and chemical biologists. Indeed, many metabolites containing such linkages are 
used clinically; including the $N$-nitrosourea-containing chemotherapeutic streptozotocin (1)(is a naturally occurring alkylating antineoplastic agent that is particularly toxic to the insulin-producing beta cells of the pancreas in mammals), the isoxazolidinone-containing antibiotic D-cycloserine (2) (is an antibiotic used to treat tuberculosis), and the nitro groupcontaining antibiotic chloramphenicol (3). X-X bond containing functional groups can be essential for the activity of natural products. For example, the $N$-nitrosourea substituent of streptozotocin is a precursor to diazomethane, which alkylates DNA. Similarly the presence of both diazo groups in lomaiviticin A (4) are required for efficient generation of DNA double strand breaks. The $N$-hydroxyl groups of siderophores e.g. aerobactin (5) are crucial for chelating insoluble ferric iron and the $\mathrm{N}-\mathrm{O}$ glycosidic linkage in calicheamicin (6) is one of the most structurally complex natural products that has been developed into an anticancer agent that is critical for optimal binding to DNA. The N-N bond of piperazic acid imparts increased conformational rigidity compared with L-proline, potentially impacting the activity of piperazic acid containing nonribosomal peptides, such as kutzneride 1 (7) (Fig. 2)(Waldman, et al., 2017).

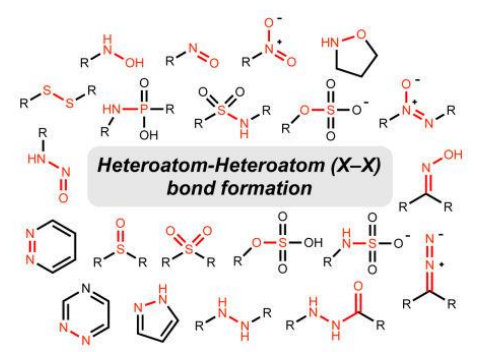

Figure (1): $\mathrm{X}-\mathrm{X}$ bond containing functional groups

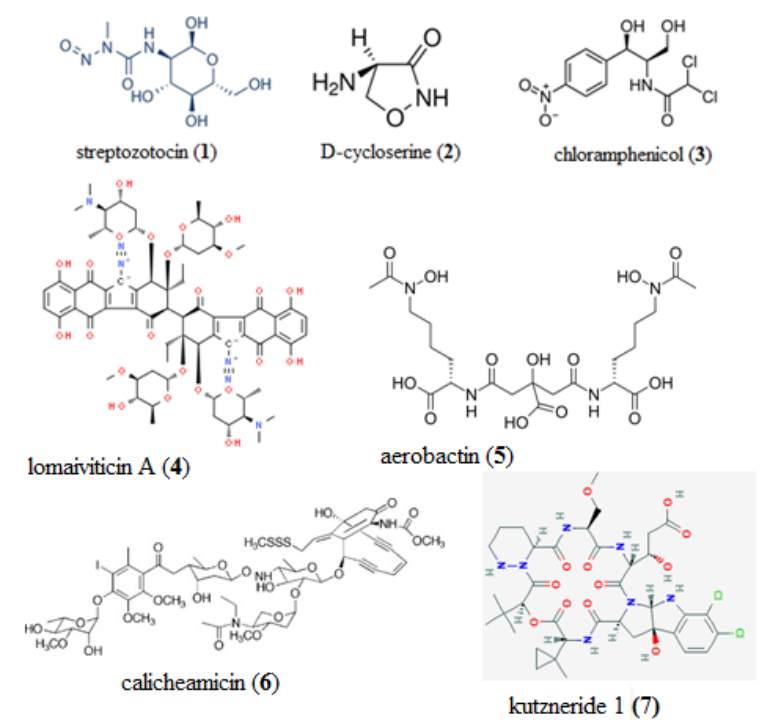

Figure (2): $\mathrm{X}-\mathrm{X}$ bond containing clinically used structures 
The S-heterocyclic core (Thiophene) has been reported to possess significant importance in various fields from medicinal chemistry to material science including pharmaceuticals, dyes, and agrochemicals. Many diverse biologically active products were prepared, several of which exhibited antimicrobial, analgesic, anti-inflammatory, antioxidant, antitumor, local anesthetic, anticoagulant and antithrombotic activities. The 2-amino-thiophene derivatives enrolled as special and important intermediates in organic syntheses providing several types of heterocyclic systems of useful applications. For the synthesis of thiophen2-amines, the subsequent introduction of the amino group into an existing thiophene moiety was found to be difficult and thus remained a challenging task. Gewald method was known as the most well-established approach for the preparation of 2-aminothiophenes, which involved the three-component reaction of $\alpha$-ketone, an activated nitrile and elemental sulfur in the presence of basic catalyst. Activated nitriles used so far in such classical reaction were cyanoacetic acid esters, malononitrile, cyanoacetohydrazides and benzoyl acetonitrile, affordingthe corresponding 3-alkoxycarbonyl-, 3-cyano-, 3-carbamoyl-, and 3benzoylthiophen-2-amines respectively. The research article aimedto synthesize some thiophene derivatives based upon newly prepared 5-acetyl-4-([4-acetylphenyl]amino)-2aminothiophene-3-carbonitrile (8) of expected antitumoragents (Schemes 1-3) against two human tumor cell lines namely; hepatocellular carcinoma (HEPG-2)and mammary gland breast cancer (MCF-7)(Table 1). A molecular modeling study was carriedout to predict the reactive sites in the thiophene moiety and the biological reactivityagainst the tested tumor cell lines(Khalifa \& Algothami, 2020).

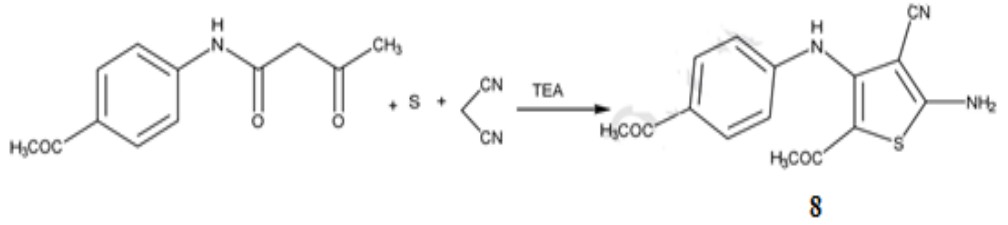

Scheme 1:Preparation of 5-acetyl-4-((4-acetylphenyl)amino)-2-aminothiophene-3carbonitrile (8)

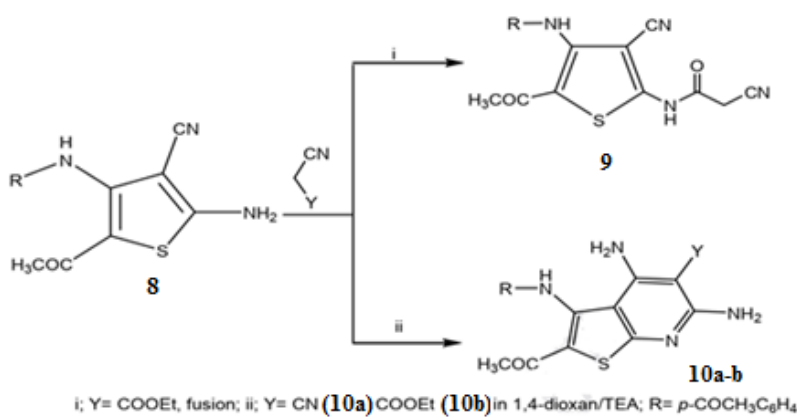

Scheme 2:Synthesis of acetamide compound (9) and thieno[2,3-b]pyridine derivatives(10ab) 


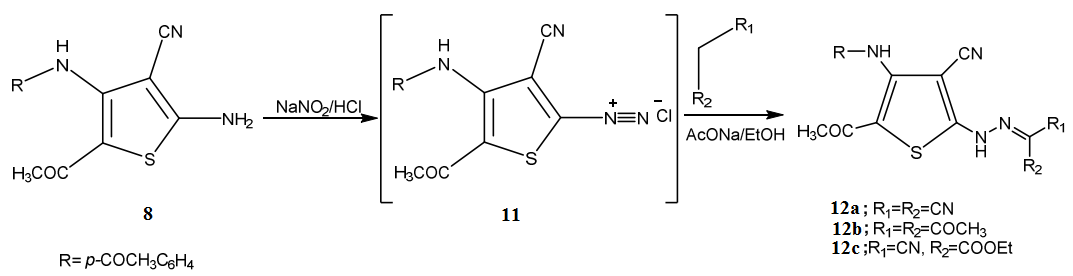

Scheme (3): Synthesis of the hydrazinyl derivatives (12a-c)

Table (1): Effect of the synthesized compounds (12a-c) on the growth of tumor cell lines under investigation comparing with positive control (Doxorubicin)

\begin{tabular}{ccc}
\hline \multirow{2}{*}{ Compd. } & \multicolumn{2}{c}{ In vitro Cytotoxicity $\mathrm{IC}_{\mathbf{5 0}}(\boldsymbol{\mu M})$} \\
& HEPG2 & MCF-7 \\
\hline Doxorubicin & $4.50 \pm 0.3$ & $4.17 \pm 0.2$ \\
$\mathbf{1 2 a}$ & $13.78 \pm 1.3$ & $15.81 \pm 1.4$ \\
$\mathbf{1 2 b}$ & $\mathbf{3 3 . 7 8} \pm \mathbf{2 . 9}$ & $42.96 \pm 3.2$ \\
$\mathbf{1 2 c}$ & $\mathbf{1 6 . 2 9} \pm \mathbf{1 . 5}$ & $17.47 \pm \mathbf{1 . 7}$
\end{tabular}

Benzothiazole derivatives (Scheme 4) have attracted a great deal of interest due to their anticancer; antitumor; anticonvulsant; antiviral; antibacterial; antimicrobial; and fungicidal activities. They are also useful as anti-allergic, anti-inflammatory and anthelmintic agents and as appetite depressants, intermediates for dyes, plant protectants, histamine H2antagonists and photographic sensitizers. On the other hand, careful literature survey revealed that thiazole, thiophene and pyrazole ring systems have occupied a unique position in the design and synthesis of novel biologically active agents with remarkable analgesic and anti-inflammatory activities in addition to their well-documented potential antimicrobial activities (Bondock, et al., 2010).

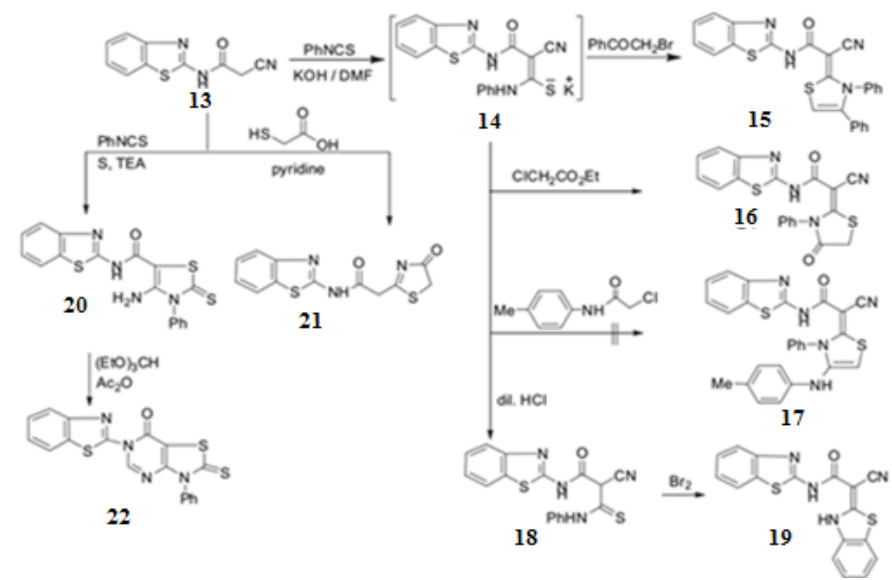

Scheme (4): Synthetic route fordifferent thiazoles 
Nitrogen-based heterocyclic chemistry is an important and unique class among the applied branches of organic chemistry, with a significant amount of research dedicated to the development of novel molecules and composites. Many $N$-heterocyclic compounds that are broadly distributed in nature, possess physiological and pharmacological properties and are constituents of many biologically important molecules, including many vitamins, nucleic acids, pharmaceuticals, antibiotics, dyes and agrochemicals, amongst many others. The base pairs of DNA and RNA (Guanine, cytosine, adenine, and thymine) are also made up of $N$ heterocyclic compounds, namely purines, pyrimidines, etc. These nitrogencontaining heterocyclic molecules with distinct characteristics and applications have gained prominence in the rapidly expanding fields of organic and medicinal chemistry and the pharmaceutical industry. Furthermore, the electron-rich nitrogen heterocycle is not only able to readily accept or donate a proton, but it can also easily establish diverse weak interactions (Martins et al., 2015).

A glance at the FDA databases reveals the structural significance of nitrogen-based heterocycles in drug design and engineering of pharmaceuticals. Nearly $75 \%$ unique smallmolecule drugs contain a nitrogen heterocycle. The $N$-heterocyclic skeletons feature significantly various classes of therapeutic applications and are used as the building blocks of a number of new drug candidates, due to the ability of the nitrogen atom to easily form hydrogen bonding with biological targets. A vast number of nitrogen-containing heterocyclic compounds are known to exhibit a wide range of pharmacological activities including anticancer, anti-HIV, antimalarial, anti-tubercular, anti-microbial and diabetic activities. A measure of their importance in the design of nitrogen heterocycles can be seen by the over 97,400 publications on nitrogen heterocycles that have appeared between 2009 and early 2020, as illustrated in (Fig. 3), of which 12,615 publications have been reported in the year 2019(Kerru, et al., 2020).

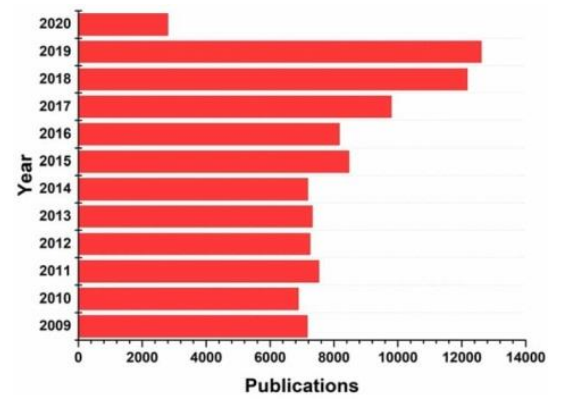

Figure (3):Publications on nitrogen-based heterocycles from2009 to early 2020

Reactions of cyanoacetic acid hydrazide with numerous reactants (Nucleophiles and electrophiles) are used in synthesis of a variety of polyfunctional heterocyclic compounds of biological interest(Fig. 4). Cyano-acetohydrazide has a hydrazine component. Hydrazines and their derivatives constitute an important class of compounds that has found wide utility in 
organic synthesis. The chemistry of the carbon-nitrogen double bond (Schemes5\&6)of hydrazoneis becoming the backbone of condensation reactions in benzo-fused $N$ heterocycles, which also constitute an important class of anticancer agents. Many derivatives exhibited potent anticancer activities against liver and breast cancer cell lines compared to doxorubicin(Tables $2 \mathbf{\& 3}$ ). Ithas been claimed that a number of hydrazide hydrazone(Fig. 5)derivatives possess interesting bioactivity. Reaction of cyanoacetohydrazide withvarious reactants results in unique properties, many of which are still unknown(Hosseini \& Bayat, 2018).

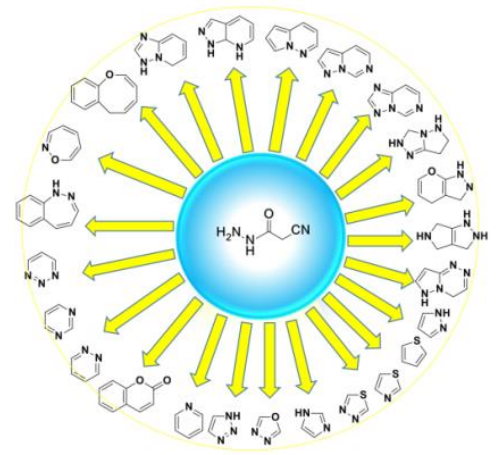

Fig. (4): Summary of various heterocyclic compounds synthesized using cyanoacetohydrazide

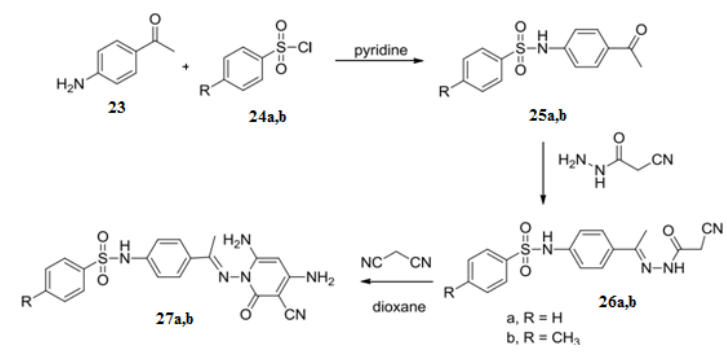

Scheme (5): Sulfonamide with pyridine moiety $(\mathrm{C}=\mathrm{N}$ bond) as anti-liver cancer compounds

Table (2): In vitro anticancer screening of the synthesized compounds 15, 16, 17 against human liver cancer cell line HepG2

\begin{tabular}{clllll}
\hline Cpd. no. & \multicolumn{2}{l}{ Compound concentration $(\mu \mathrm{M})$} & \multirow{2}{*}{ IC $_{50}(\mu \mathrm{M})$} \\
\cline { 2 - 5 } & \multicolumn{3}{l}{$\begin{array}{l}12.5 \\
\text { Surviving fraction }(\text { mean } \pm \mathrm{SE})^{\mathrm{a}}\end{array}$} & & \\
& & & & \\
\hline Doxorubicin & $0.721 \pm 0.020$ & $0.546 \pm 0.020$ & $0.461 \pm 0.010$ & $0.494 \pm 0.030$ & 36.3 \\
25a & $0.891 \pm 0.085$ & $0.719 \pm 0.028$ & $0.464 \pm 0.067$ & $0.417 \pm 0.030$ & 35.3 \\
25b & $1.048 \pm 0.073$ & $0.726 \pm 0.068$ & $0.547 \pm 0.247$ & $0.367 \pm 0.116$ & 35.8 \\
26a & $0.881 \pm 0.054$ & $0.778 \pm 0.056$ & $0.361 \pm 0.023$ & $0.242 \pm 0.025$ & 28.0 \\
26b & $0.837 \pm 0.027$ & $0.530 \pm 0.058$ & $0.349 \pm 0.042$ & $0.293 \pm 0.026$ & 26.0 \\
27a & $0.748 \pm 0.049$ & $0.556 \pm 0.009$ & $0.312 \pm 0.044$ & $0.321 \pm 0.023$ & 25.5
\end{tabular}


Also, hydrazide-hydrazones and their derivatives are important class of compounds which are used in organic synthesis. As antibiotic resistant organisms have become more common place, the pipeline for the discovery of new antimicrobial agents has decreased. The pharmacological profiles are their antimicrobial; anti-tubercular; anticonvulsant; antiinflammatory; antidepressant; analgesic and antitumor (Fig. 4\&5)activities. Few hydrazones act as orally effective drugs for the treatment of iron overload disease or genetic disease-thalassemic. We focused our work on developing novel poly-functionalized heterocyclic compounds with potential bioactivity (Jadeja et al., 2015).

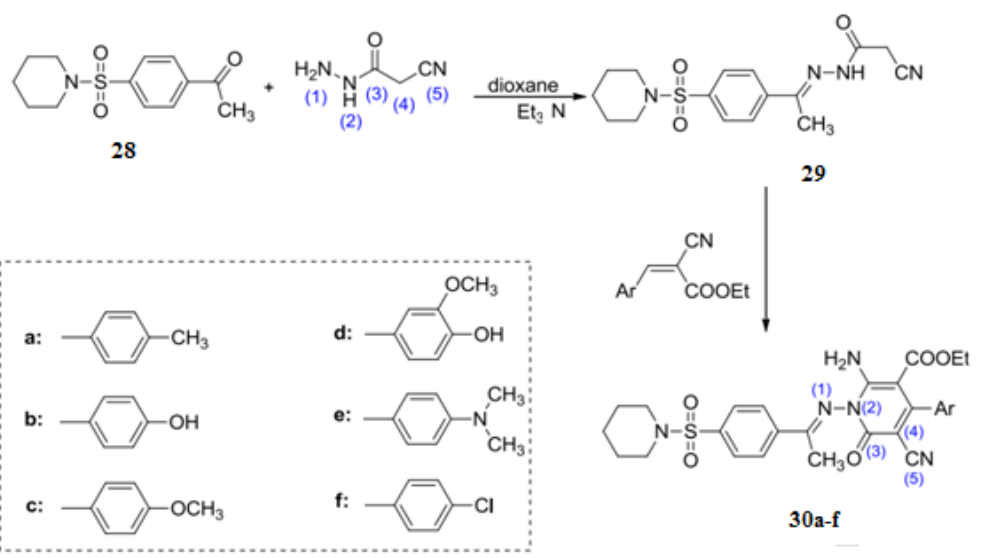

Scheme (6): 1,2-Dihydropyridines as anti-breast cancer compounds

Table (3):In vitro anticancer screening of synthesized compounds 20b, 20f against human breast cell lineMCF7

\begin{tabular}{llllll}
\hline Cpd. no. & \multicolumn{4}{l}{ Compound concentration $(\mu \mathrm{M})$} & $\mathrm{IC}_{50}(\mu \mathrm{M})$ \\
\cline { 2 - 5 } & 10 & 25 & 50 & 100 & \\
& \multicolumn{2}{l}{ Surviving fraction $(\operatorname{mean} \pm \mathrm{SE})^{\mathrm{a}}$} & & & \\
\hline Doxorubicin & $0.721 \pm 0.020$ & $0.546 \pm 0.020$ & $0.461 \pm 0.010$ & $0.494 \pm 0.030$ & 32.02 \\
30b & $0.925 \pm 0.032$ & $0.647 \pm 0.024$ & $0.681 \pm 0.023$ & $0.641 \pm 0.015$ & $\mathbf{2 5 . 5}$ \\
30f & $0.818 \pm 0.044$ & $0.723 \pm 0.012$ & $0.622 \pm 0.014$ & $0.553 \pm 0.065$ & $\mathbf{2 0 . 6}$ \\
\hline
\end{tabular}




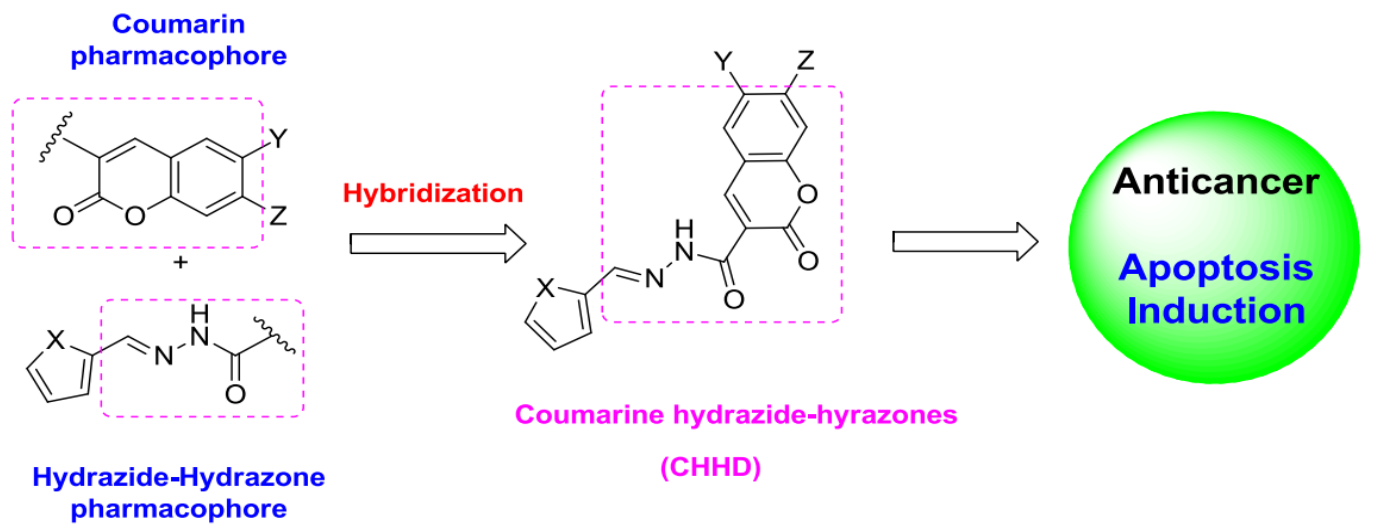

Fig. (5):The most potent CHHDs against Hep-G2 cancer cell line

Many pyrazole derivatives (Scheme 7)have attracted considerable attention in the recent years for their diverse biological activities. They are also acknowledged for their anticancer activities(Table 4). Moreover, the chemistry of fused pyrazolo- and thienopyrazole derivatives has drawn great attention due to their pharmacological importance. Such excellent pharmacology encouraged us to synthesize novel pyrazole derivatives with evaluation of their antitumor activities (Mohareb et al., 2012).

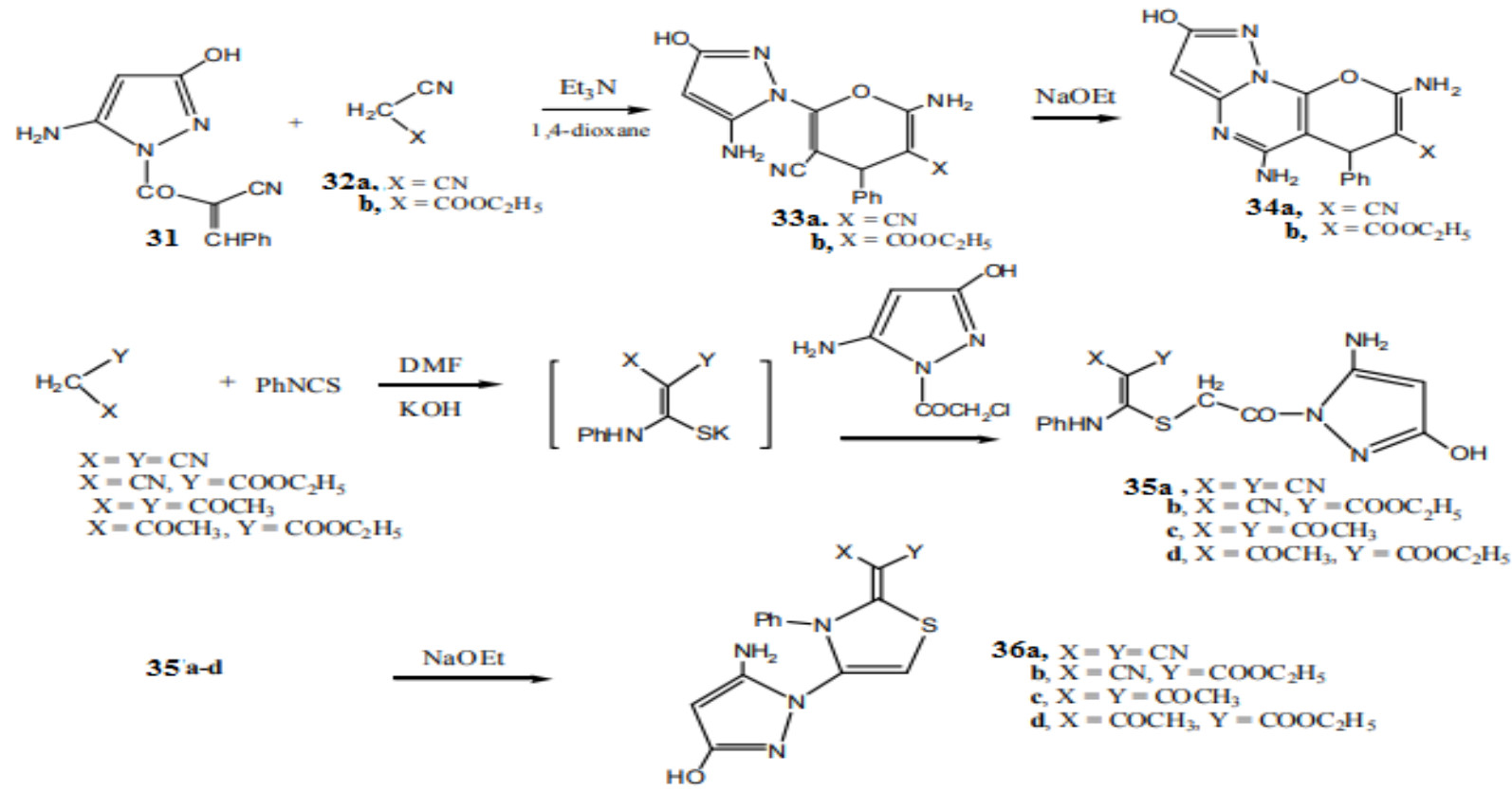

Scheme (7):Pyrazole derivatives as anticancer compounds 
Table (4):In vitro anticancer screening of synthesized compounds 31-36

\begin{tabular}{|c|c|c|c|}
\hline \multirow{2}{*}{ Compound } & \multicolumn{3}{|c|}{ GI $_{\text {50 }}$ (mol L $^{-\mathbf{1}}$ ) } \\
\cline { 2 - 4 } & MCF-7 & NCI-H460 & SF-268 \\
\hline 34a & $0.01 \pm 0.001$ & $0.01 \pm 0.008$ & $0.02 \pm 0.001$ \\
34b & $16.0 \pm 3.6$ & $20.0 \pm 2.4$ & $18.5 \pm 6.0$ \\
35a & $50.6 \pm 12.9$ & $36.4 \pm 8.8$ & $44.8 \pm 6.6$ \\
35b & $0.1 \pm 0.02$ & $0.4 \pm 0.01$ & $0.4 \pm 0.08$ \\
35c & $12.4 \pm 8.2$ & $10.1 \pm 2.8$ & $8.2 \pm 1.8$ \\
35c & $6.2 \pm 1.6$ & $4.2 \pm 1.8$ & $2.7 \pm 0.6$ \\
35d & $0.2 \pm 0.01$ & $0.1 \pm 0.06$ & $0.3 \pm 0.05$ \\
36a & $0.02 \pm 0.008$ & $0.03 \pm 0.008$ & $0.01 \pm 0.004$ \\
36b & $20.0 \pm 3.6$ & $22.0 \pm 2.4$ & $31.5 \pm 8.0$ \\
36c & $0.03 \pm 0.006$ & $0.01 \pm 0.006$ & $0.03 \pm 0.005$ \\
36d & $1.9 \pm 0.9$ & $0.6 \pm 1.8$ & $0.8 \pm 0.08$ \\
Doxorubicin & $0.04 \pm 0.008$ & $0.09 \pm 0.008$ & $0.09 \pm 0.007$ \\
\hline
\end{tabular}

Pyridine derivatives are currently an important group of organic compounds that are used as bactericides, fungicides, and anticancer agents. Furthermore, 2-pyridones represent a unique class of pharmacophores (Fig. 6), found in various therapeutic agents. Pyridine and its substructures are widely scattered anddominantly found in natural products, pharmaceuticals, vitamins, and other functional as well as essential materials(Hosseini \& Bayat, 2018). Pyridines have been reported as biologically interesting molecules and precursors for the synthesis of triazolo[1,5-a]pyridines. Several methods have previously described the synthesis of triazolo[1,5-a]pyridines from 1,6-diaminopyridines. Moreover, triazolo[1,5-a]pyridine systems are reported to be useful compounds as pharmaceuticals, fluorescent brighteners, completing agents, herbicides, cyan dye mixture for thermal color proofing, and as jet-printing ink agents. Recently, derivatives of this ring system are prepared from $N$-arylmethylidene-2-cyanohydrazide. Triazolo[1,5- $a$ ]pyridines have also been prepared by ring transformation of triazolo[4,3-a]pyridineand from 2-thioxopyrones (Basyouni, 2003).

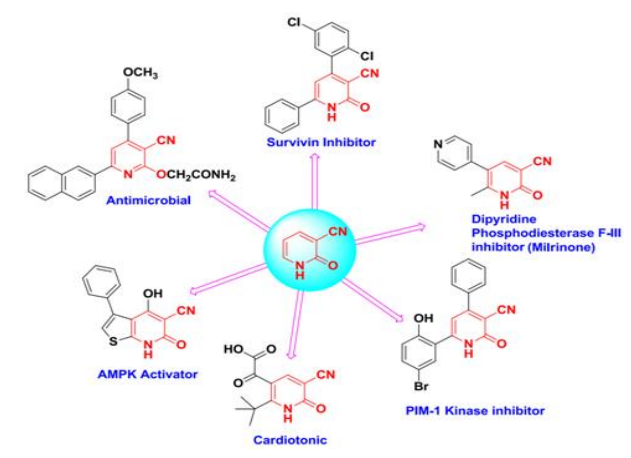

Fig. (6): 2-Pyridones as a pharmacophore for various pyridine heterocyclic compounds

There are numerous reports available in the literature, which indicate the potential. 6-(4-Hydroxy-2-methyl-phenyl)-2-( $p$-sulfamylphenyl)-4,5-dihydropyridazine-3(2H)-one showed high activity against HL-60 (TB) (Leukemia), anticancer effects of pyridazinonesSR (Leukemia), NCIH522 (non-small-cell lung cancer), and BT-549 (Breast 
cancer), the $p$-methoxydichloropyridazone displayed a good inhibition of tumor growth in mice for the resistant MAC16 cell line. Some diphenylpyridazine derivatives (Particularly NSC 351478) (Fig. 7)were effective in the treatment of P388 leukemia in mice. The substituents at position 2 of the pyridazinone ring do not fall into a clear pattern; alterations at this position can have major effects on the activity of the resulting compounds. Hydrazides are very useful starting materials for the construction of several heterocyclic compounds such as 1,3,4-oxadiazoles, 1,3-thiazoles, 1,3,4-thiadiazoles, 1,2,4triazoles, 1,2,4-triazolo[3,4- $b]$-1,3,4-thiadiazoles 1,2,4-triazolo[3,4- $b]$-1,3,4-thiadiazines, pyrroles and pyrazoles(Shaker \& Marzouk, 2016).

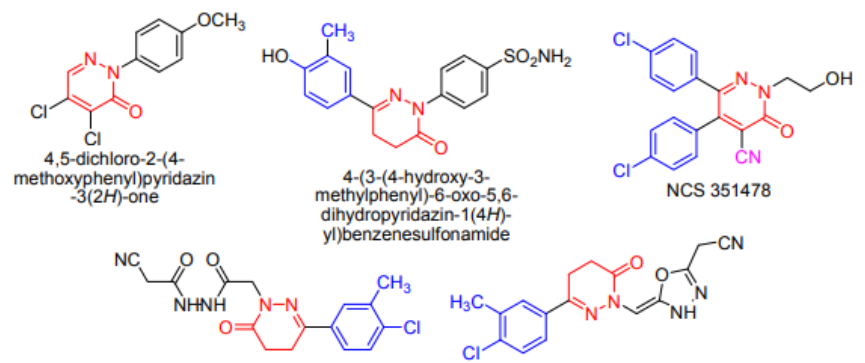

Fig. (7):Anticancer pyridazine derivatives

Quinolines and their derivatives with specific substituents at appropriate positions have attracted much interest in synthetic and medicinal chemistry. They have a wide range of chemotherapeutic activity including antimicrobial, antimalarial, antitumor, antiinflammatory and antiparasitic activity. Among quinolines, 2-chloro-3-formylquinolines38 (Scheme 8) are versatile precursors and have been used as building blocks for synthesis of annulated quinolines(Scheme 9)with potential biological activity. Several quinoline derivatives showed potent anticancer activities against breast cancer cell lines (Table 5)(Bondock, 2015).

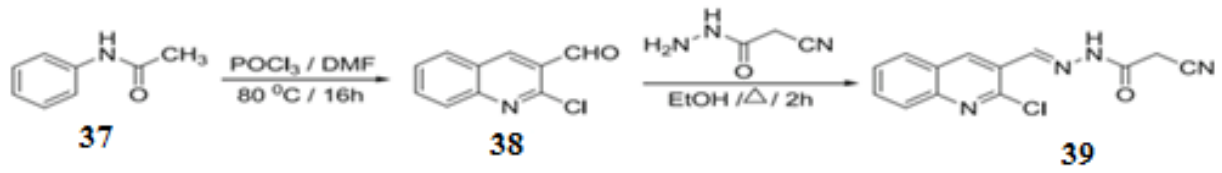

Scheme (8): Synthesis of $N^{\prime}$-((2-chloroquiolin-3-yl) methylene)-2-cyanoacetohydrazide

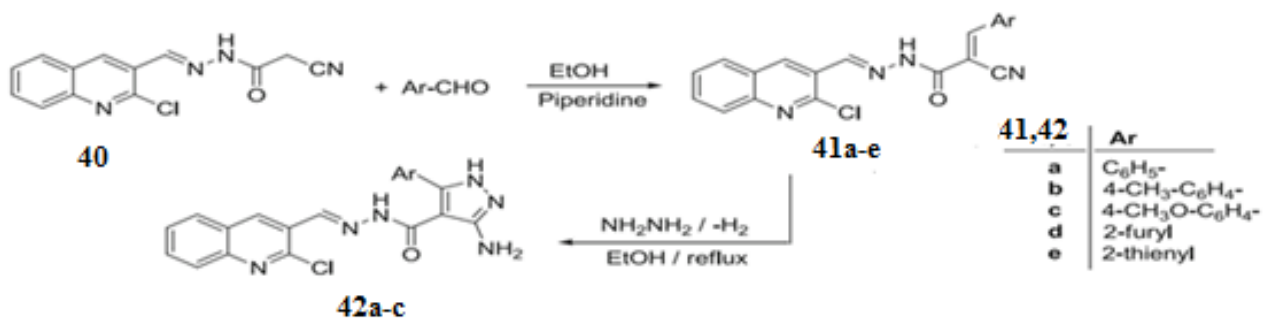

Scheme (9): Synthetic route to pyrazole derivatives 19a-c 
Table (5): Cytotoxicity $\left(\mathrm{IC}_{50}\right)$ of the tested compounds against MCF-7 cell lines

\begin{tabular}{cc}
\hline Compounds & $\mathrm{IC}_{50}(\mu \mathrm{g} / \mathrm{mL})^{\mathrm{a}}$ \\
\cline { 2 - 2 } & $\mathrm{MCF}-7$ \\
\hline 40 & $20.45 \pm 2.18$ \\
$41 \mathrm{a}$ & $6.67 \pm 1.18$ \\
$41 \mathrm{~b}$ & $0.010 \pm 0.006$ \\
$42 \mathrm{~b}$ & $22.05 \pm 10.22$ \\
$42 \mathrm{c}$ & $33.60 \pm 4.60$
\end{tabular}

Tetrahydroquinolines are important building blocks in synthetic heterocyclic chemistry and their use in the preparation of pyrazole[3,4-b]quinolines and benzo[b]naphthyridine derivatives has been reported recently. Pyrazolo[3,4- $b$ ]quinoline derivatives are used as pharmaceutical agents and as inhibitors of oncogenic Ras (RAS proteins are essential components of signalling pathways that emanate from cell surface receptors). Interesting pharmacological properties have also been associated with benzo[b]naphthyridine derivatives, which possess antitumor, trypanocidal and DNA binding properties and are antimicrobial agents (Elkholy, 2007).

Thiazoles are aromatic five-membered heterocyclic compounds that contain sulfur and nitrogen at position 1 and 3, respectively. They are involved in many of the natural products for example; the thiazolium nucleus is a component of vitamin thiamin (B1) and thiamine pyrophosphate (TPP) (Abdel-Galil, et al., 2018).

One of the most powerful heterocyclic compounds is 1,3-thiazole ring, which exhibited potent anticancer activity against various types of cancer. Also, pyrazolylthiazoles(Scheme 10)showed anticancer activity against human malignant hepatoma HepG2, MCF-7, and human lung cancer. The outcomes showed that some of the tested samples revealed powerful activity against human breast cancer cell line(Table 6)(Abbas, et al., 2017).

Thiazoles and their derivatives have attracted continuing interest over the years because of their varied biological activities, recently found application in drug development for the treatment of allergies; hypertension; inflammation; schizophrenia; bacterial; HIV infections; hypnotics and more recently for the treatment of pain, as fibrinogen receptor antagonists with antithrombotic activity and as new inhibitors of bacterial DNA gyrase B (Gouda, et al., 2010). 


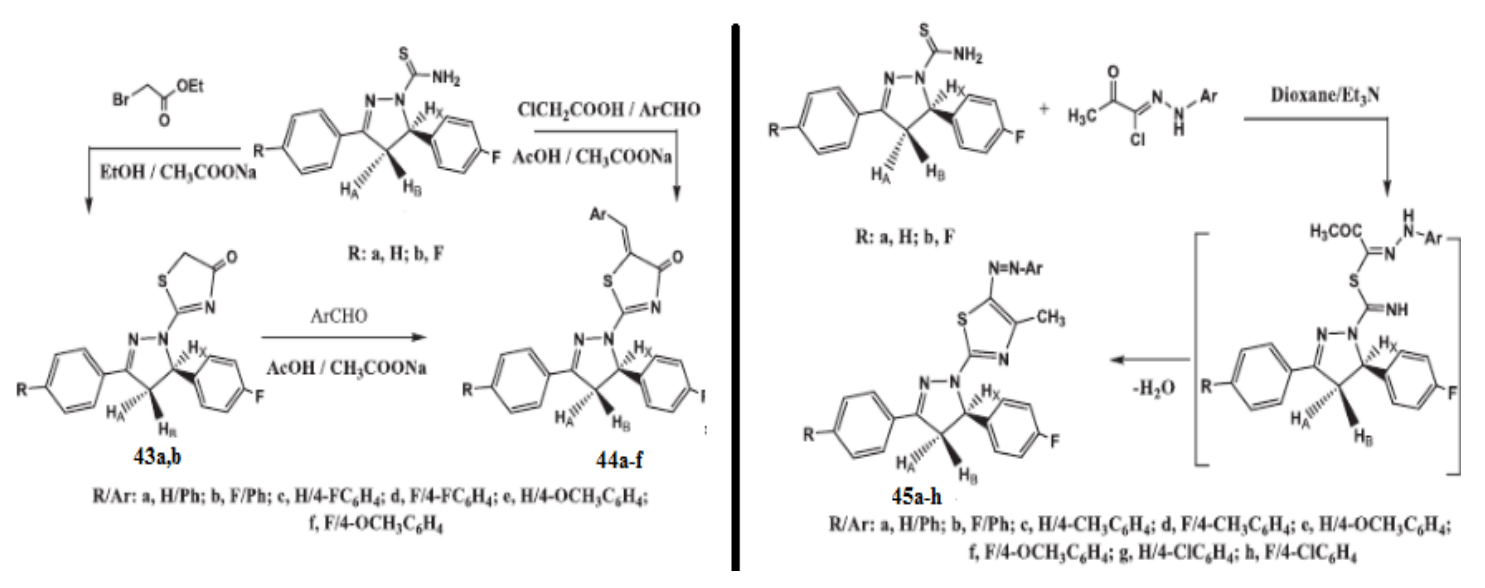

Scheme (10):PyrazolylthiazolesasPotentialAnti-BreastCancerAgents

Table (6): Cytotoxicity $\left(\mathrm{IC}_{50}\right)$ of the tested compounds against MCF-7 cell lines

\begin{tabular}{crcr}
\hline Compound & $\mathrm{IC}_{50}(\mu \mathrm{g} / \mathrm{mL})$ & Compound & $\mathrm{IC}_{50}(\mu \mathrm{g} / \mathrm{mL})$ \\
\hline $\mathbf{4 4 a}$ & $11.60 \pm 1.22$ & $\mathbf{4 5 d}$ & $9.90 \pm 1.22$ \\
$\mathbf{4 4 c}$ & $8.11 \pm 0.82$ & $\mathbf{4 5} \mathbf{e}$ & $10.00 \pm 1.11$ \\
$\mathbf{4 4 d}$ & $8.33 \pm 0.87$ & $\mathbf{4 5 f}$ & $8.65 \pm 0.90$ \\
$\mathbf{4 4 e}$ & $8.77 \pm 1.00$ & $\mathbf{4 5 g}$ & $8.10 \pm 0.80$ \\
$\mathbf{4 5 a}$ & $32.10 \pm 3.32$ & $\mathbf{4 5 g}$ & $31.32 \pm 3.50$ \\
$\mathbf{4 5} \mathbf{c}$ & $28.00 \pm 3.00$ & Tamoxifen & $8.00 \pm 0.94$ \\
\hline
\end{tabular}

Thiazole derivatives have gained considerable attention because of their broad biological activities that include antidiabetic, antimicrobial, anti-inflammatory, anticancer, antiAlzheimer, antihypertensive, antioxidant and hepatoprotective activities. In addition, many thiazole-containing drugs such as Abafungin, Alagebrium, Acotiamide, Amiphenazole, Brecanavir, Cefepime, Carumonam and Cefmatilen are commercially available. Different thiazolylpyrazoles (Scheme 11) showed a weak hepatoprotective effect (Table 7) against $\mathrm{CCl}_{4}$-induced liver damage suggesting their usage as a candidate starting materials for the synthesis of more potent hepatoprotective drugs(Abu-Melha et al., 2019).

Table (7): Cytotoxic activity of the synthesized thiazolylpyrazoles against HepG-2, HCT116 and $\mathrm{MCF}-7$ cell, expressed as $\mathrm{IC}_{50}$ values and compared to doxorubicin the standard drug. 


\begin{tabular}{lrcc}
\hline \multirow{2}{*}{ Compounds } & \multicolumn{3}{c}{$\mathrm{IC}_{50}(\mu \mathrm{g} / \mathrm{mL})$} \\
\cline { 2 - 4 } & \multicolumn{1}{c}{ HepG-2 } & HCT-116 & MCF-7 \\
\hline 46c & $13.1 \pm 0.4$ & $25.4 \pm 1.3$ & $13.9 \pm 0.9$ \\
46d & $11.4 \pm 0.2$ & $14.8 \pm 0.6$ & $7.36 \pm 0.4$ \\
$\mathbf{4 6 g}$ & $7.4 \pm 0.2$ & $11.8 \pm 0.5$ & $3.77 \pm 0.2$
\end{tabular}

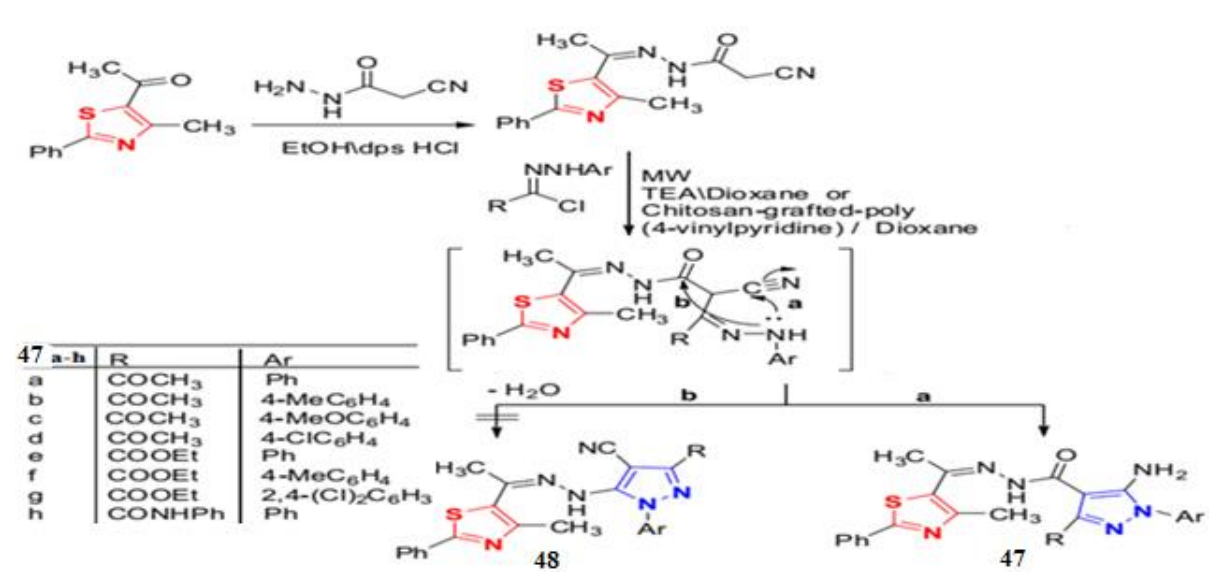

Scheme (11): Synthesis of thiazolylpyrazoles47a-h

\section{REFERENCES}

Abbas, E. M., Dawood, D. H., Farghaly, T. A., El-hag, F. A., \& Ali, M. M. J. J. o. H. C. (2017). Synthesis and Structure-Activity Relationship Study of Novel Pyrazolylthiazoles as Potential Anti-Breast Cancer Agents. 54(3), 1974-1982.

Abdel-Galil, E., Moawad, E. B., El-Mekabaty, A., \& Said, G. E. J. S. C. (2018). Synthesis, characterization and antibacterial activity of some new thiazole and thiazolidinone derivatives containing phenyl benzoate moiety. 48(16), 2083-2092.

Abu-Melha, S., Edrees, M. M., Salem, H. H., Kheder, N. A., Gomha, S. M., \& Abdelaziz, M. R. J. M. (2019). Synthesis and Biological Evaluation of Some Novel Thiazole-Based Heterocycles as Potential Anticancer and Antimicrobial Agents. 24(3), 539.

Basyouni, W. M. J. A. c. s. (2003). Synthesis of novel substituted [1, 2, 4] triazolo [1, 5-a] pyridines and their related pyrano [2, 3-d] imidazole derivativs. 50(2), 223-238.

Bondock, S., Fadaly, W., \& Metwally, M. A. J. E. j. o. m. c. (2010). Synthesis and antimicrobial activity of some new thiazole, thiophene and pyrazole derivatives containing benzothiazole moiety. 45(9), 3692-3701. 
Driowya, M., Saber, A., Marzag, H., Demange, L., Benhida, R., \& Bougrin, K. J. M. (2016). Microwave-assisted synthesis of bioactive six-membered heterocycles and their fused analogues. 21(4), 492.

Elkholy, Y. M. J. M. (2007). An Efficient Synthesis of Pyrazolo [3, 4-b] quinolin-3-amine and Benzo $[\mathrm{b}][1,8]$ naphthyridine Derivatives. 12(3), 361-372.

Gouda, M., Berghot, M., El-Ghani, G. E. A., \& Khalil, A. J. E. j. o. m. c. (2010). Synthesis and antimicrobial activities of some new thiazole and pyrazole derivatives based on 4, 5, 6, 7-tetrahydrobenzothiophene moiety. 45(4), 1338-1345.

Hosseini, H., \& Bayat, M. J. T. i. C. C. (2018). Cyanoacetohydrazides in Synthesis of Heterocyclic Compounds. 376(6), 40.

Jadeja, J., Mamtora, M., Gondaliya, M., Manawar, R., Shah, M. K. J. I. L. o. C., Physics, \& Astronomy. (2015). Synthesis, Spectral Analysis and Evolution of Antimicrobial Activity of Schiff Base of Cyanoacetohydrazide. 52, 100--110.

Kerru, N., Gummidi, L., Maddila, S., Gangu, K. K., \& Jonnalagadda, S. B. J. M. (2020). A Review on Recent Advances in Nitrogen-Containing Molecules and Their Biological Applications. 25(8), 1909.

Khalifa, M. E., \& Algothami, W. M. J. J. o. M. S. (2020). Gewald synthesis, antitumor profile and molecular modeling of novel 5-acetyl-4-((4-acetylphenyl) amino)-2aminothiophene-3-carbonitrile scaffolds. 1207, 127784.

Martins, P., Jesus, J., Santos, S., Raposo, L. R., Roma-Rodrigues, C., Baptista, P. V., \& Fernandes, A. R. J. M. (2015). Heterocyclic anticancer compounds: recent advances and the paradigm shift towards the use of nanomedicine's tool box. 20(9), 16852-16891.

Mohareb, R. M., El-Sayed, N. N., \& Abdelaziz, M. A. J. M. (2012). Uses of cyanoacetylhydrazine in heterocyclic synthesis: novel synthesis of pyrazole derivatives with anti-tumor activities. 17(7), 8449-8463.

Shaker, S. A., \& Marzouk, M. I. J. M. (2016). Utilization of Cyanoacetohydrazide and Oxadiazolyl Acetonitrile in the Synthesis of Some New Cytotoxic Heterocyclic Compounds. 21(2), 155.

Thomas, J., Jecic, A., Vanstreels, E., van Berckelaer, L., Romagnoli, R., Dehaen, W., Balzarini, J. J. E. j. o. m. c. (2017). Pronounced anti-proliferative activity and tumor cell selectivity of 5-alkyl-2-amino-3-methylcarboxylate thiophenes. 132, 219235. 
Waldman, A. J., Ng, T. L., Wang, P., \& Balskus, E. P. J. C. r. (2017). Heteroatomheteroatom bond formation in natural product biosynthesis. 117(8), 5784-5863.

$$
\begin{aligned}
& \text { مقالة مرجعية: أنشطة مضادة للسرطانات لبعض الوحدات المنصهرة الغير متجانسة الحلقة التى }
\end{aligned}
$$

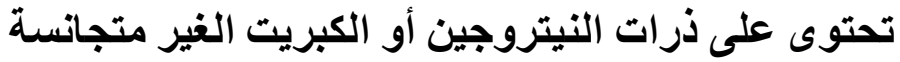

$$
\begin{aligned}
& \text { أسماء عمر2, نشوى صالح, , عادل عبد الرحمن, خالد العدل } 493 \\
& \text { 1- قسم الكيمياء ـ كلية العلوم (فرع البنات) -جامعة الأزهر ـمدينة نصر ـالقاهرة-مصر } \\
& \text { 2- قسم الكيمياء ـ كلية العلوم -جامعة المنوفية - شبين الكوم-مصر } \\
& \text { 3- قسم الكيمياء الصيدليه ــ كلية الصيدله (بنين) -جامعة الأزهر ـمدينة نصر ـالقاهرة-مصر } \\
& \text { 4- قسم الكيمياء الصيدليه ـ كلية الصيدله -جامعة هليوبوليس للتنمية المستدامة ـالقاهرة-مصر }
\end{aligned}
$$

khaled.elad1@hu.edu.eg, eladlkhaled74@azhar.edu.eg : البريد الاككتروني للباحث الرئيسي

تم فى هذا البحث مراجعة الدوريات العالمية والبحث عن النشاطات المضادة للسرطان الخاصة بالمركبات

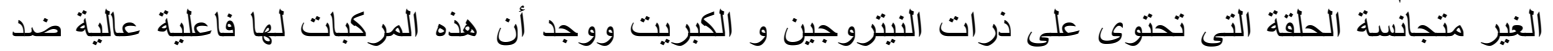

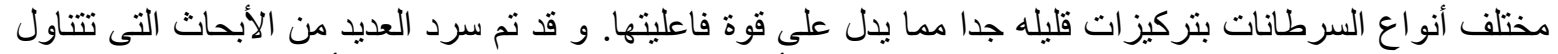

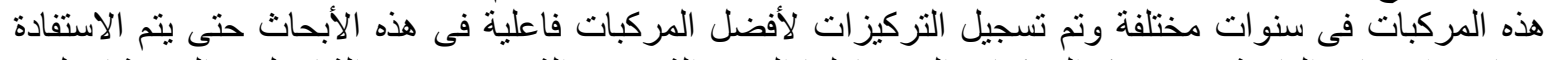

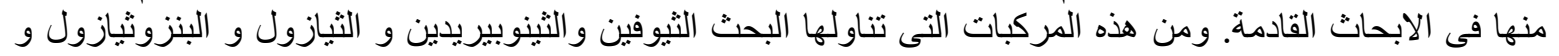

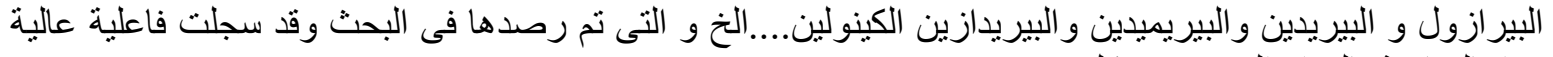

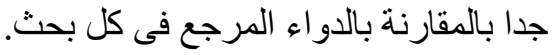

الكلمات المفتاحية : المركبات الغير متجانسة الحلقة , سرطان الثذب , سرطان خلايا الكبد , المركبات الغير متجانسة الحلقة المعتمدة علي النيتروجين , الكبريت 